\title{
Effect of welding parameters on heat generation mechanisms in friction stir welding of AA5083 aluminium alloy
}

\begin{abstract}
Friction Stir Welding (FSW) is a solid-state welding process which has revolutionized several industries in the last thirty years. The heat needed to produce the joint is generated by friction at the tool-workpiece interface and plastic deformation of the material, being affected by parameters like tool rotational speed, travel speed, axial load and tool geometry, among others. The objective of this work was to analyse the energy transformations during FSW of AA5083 aluminium alloy in order to achieve a better comprehension of the whole process, and particularly the heat generation mechanisms and material flow, which will define the quality of the joint. Experimental measurements of process parameters and conceptual analytical and numerical models were implemented. Consumed electric current, axial load and thermal cycles were acquired during FSW of AA5083 plates, for different rotational and travel speeds. From these measurements, different magnitudes (heat and torque) associated to the energy transformations were calculated. The relationships between welding parameters, generated heat and torque, sticking and sliding components and contact condition were analysed and related with material flow. The sticking heat was always higher than the sliding one, even when contact condition was closer to pure sliding. For a giving heat input, a higher sticking component produced an increase in the material flow.
\end{abstract}

Keywords: axial load, thermal cycles, heat, torque, sticking, sliding
Volume 5 Issue 4 - 202I

\author{
Leonardo Nicolás Tufaro,' Luciano Buglioni,' \\ Hernán Gabriel Svoboda ${ }^{2,3}$ \\ 'Centro de Investigación y Desarrollo en Mecánica, Instituto \\ Nacional de Tecnología Industrial \\ ${ }^{2}$ Instituto de Tecnologías y Ciencias de la Ingeniería, Universidad \\ de Buenos Aires-CONICET,Argentina \\ ${ }^{3}$ Consejo Nacional de Investigaciones Científicas y Técnicas \\ (CONICET), Argentina
}

\begin{abstract}
Correspondence: Leonardo Nicolás Tufaro, Centro de Investigación y Desarrollo en Mecánica, Instituto Nacional de Tecnología Industrial.Av. Gral. Paz 5445, BI650KNA, San Martín,
\end{abstract} Buenos Aires, Argentina, Email Itufaro@inti.gob.ar

Received: August 06, 202I | Published: August 23, 2021

\section{Introduction}

Friction Stir Welding (FSW) is a welding process in solid phase, which has become the most important research subject of welding science and technology in the last years. Particularly, it has found numerous applications in joining aluminium alloys for welded structures in industries such as aeronautical and aerospace, automotive and shipbuilding, among others. The heat needed to produce the required plastic flow is generated by the friction at the tool-work piece interface and also by the plastic deformation of the material, being affected by factors such as rotational and travel speeds, axial load and tool geometry, among others. ${ }^{1-3}$ Colligan \& Mishra ${ }^{4}$ proposed a conceptual model for process variables related to heat generation in FSW. As can be stated from this model, frictional stress and plastic flow stress are involved in torque and heat generation, responsible for the established thermal field, which also affect the first mentioned aspects. This interdependency shows the complexity of the heat generation study in this process. Schmidt et al..$^{5}$ developed an analytical model for heat generation in FSW, being the most important difference with some pre-existent models the consideration of the contact condition at the interface through a dimensionless contact state parameter. This parameter is defined as the ratio between the stirred material velocity and the tool velocity at the interface, which can be called sticking rate $(\delta) .{ }^{6}$ When contact condition is pure sticking $\delta$ is 1 , and when contact condition is pure sliding $\delta$ is $0 ., 5,6$

Finally, it is important to note that the heat generated due to plastic deformation is in essence a volumetric heat flux, which can be modelled in that way in fully coupled thermo-mechanical or computational fluid dynamics (CFD) models., ${ }^{3,10,11}$ In thermal models, this heat can be considered as a surface heat flux at the tool-workpiece interface like in the analytical model of Schmidt et al. ${ }^{5}$ used in this work. ${ }^{3,5,10}$ Recently, some authors have performed experimental measurements of different parameters such as torque, axial load and thermal cycles during FSW of aluminium alloys, which have been used with analytical and numerical models to analyse the generation and transfer of heat during this process. ${ }^{3,5,7,9,12-16}$ Despite the significant contribution of these investigations to this subject, it has not been reached yet a full understanding of the different energetic transformations during FSW. The aim of this work has been to perform a comprehensive analysis of the energy transformations during FSW of AA5083 aluminium alloy, through experimental measurements of electrical current, axial load and thermal cycles during welding and simple analytical and numerical models, to reach a large and better understanding of the effect of welding parameter on the different mechanisms of heat generation and material flow. In this way, from experimental measurements and simple analytical and numerical models it was proposed a methodology to quantify the magnitudes associated to these transformations, with the purpose to achieve a better understanding of the friction stir welding phenomena, as a previous instance to the development and analysis of more complex numerical models. In particular, although the sticking and sliding components of the generated heat and torque were taken into account in models of other works, in general the magnitude of each component and the effect of the variation of the contact condition on them were not analysed. In contrast, it was an objective of this work to quantify the sticking rate and each component of heat and torque, which could be useful in the optimization of the welding procedure as Arora et al. Proposed, ${ }^{8}$ through a better understanding of the effect of welding parameters on these aspects. These concepts are not discussed enough in the literature. Finally, it was aimed to correlate this sticking and sliding heat components with the material flow, considering its relationship with the quality of welded joints. 


\section{Materials and methods}

\section{Problem description}

In Figure 1 is shown a graphical representation of the energetic balance during FSW process, in which the magnitudes can be considered values of energy per unit length $(\mathrm{J} / \mathrm{mm})$. In this scheme, it can be appreciated the energy transformations and losses which take place in FSW, from the consumed electrical energy by the machine to the net heat input which produces the thermal field in the welded sample (plates). This energy transformations that take place in FSW can be divided in three stages. The first one is associated to the machine energetic balance, in which the difference between consumed electrical energy and total mechanical work $\left(W_{\text {Total }}\right)$ generated at the tool-workpiece interface (total torque $\times$ pitch) is associated to electrical and mechanical losses at the machine itself, i.e. the machine efficiency $\left(\eta_{\text {Mach }}\right) \cdot{ }^{12}$ Note that the pitch number is the ratio between the rotational speed $(\omega)$ and travel speed $(U)$. This machine efficiency is particular for each FSW equipment, but it must be considered depending on the type of measurements that can be done to characterize the process (i.e.: consumed electrical current). ${ }^{9}$ The second stage, associated to the heat generation at the tool-workpiece interface, is represented by the Schmidt et al. analytical model for the generated power $\left(Q_{\text {Total }}\right)$, expressed in Equation 1.

$Q_{\text {Total }}=\frac{2}{3} \pi \cdot \omega\left[\delta \cdot \frac{\sigma_{y}}{\sqrt{3}}+(1-\delta) \mu \cdot p\right]\left[\left(R_{s}{ }^{3}-R_{p}{ }^{3}\right)(1+\tan \alpha)+R_{p}{ }^{3}+3 R_{p}{ }^{2} H_{p}\right]$

FSW Machine

Heat Generation

Heat Transfer

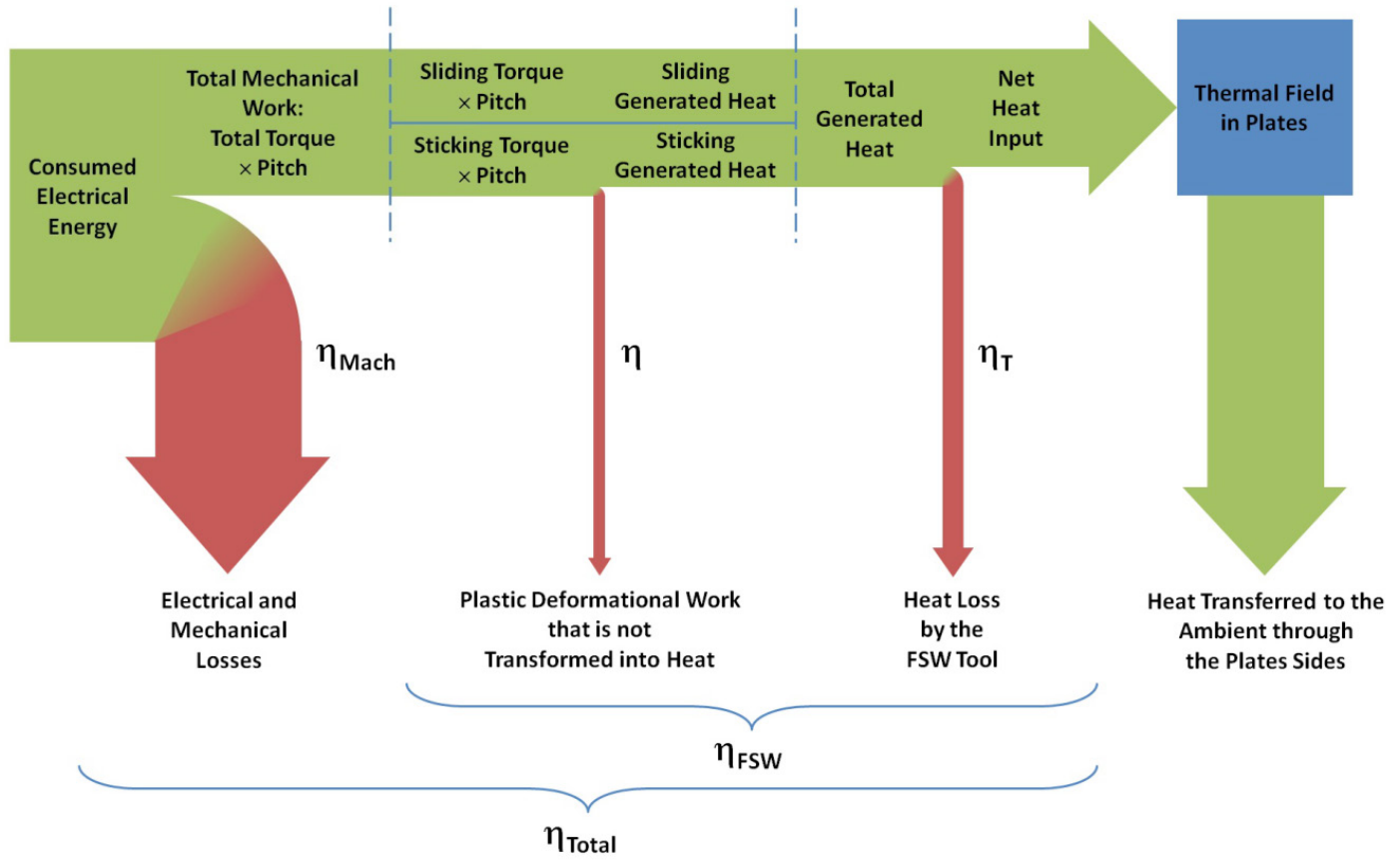

Figure I Energy transformations during FSW.

This model is a function of rotational speed $(\omega)$, shoulder radius $\left(R_{s}\right)$, pin radius $\left(R_{p}\right)$, pin height $\left(H_{p}\right)$ and shoulder cone angle $(\alpha)$, among others. Yield stress $\left(\sigma_{y}\right)$, friction coefficient $(\mu)$, contact pressure $(p)$ and sticking rate $(\delta)$ are considered uniform along all tool-workpiece interface. ${ }^{3,4,6}$ This is the major limitation of this analytical model, which can only be solved with numerical models. ${ }^{3}$ In this sense, in the recent years numerical models had been developed considering these parameters non-uniform along this interface and within the workpiece. ${ }^{7-9}$ Furthermore, to the Schmidt et al. ${ }^{5}$ model was added the mechanical efficiency $(\eta)$, which indicates the fraction of plastic strain work which is converted to heat and which value is generally $0 .{ }^{9,6-8}$ although other authors have used lower values. ${ }^{9}$ In this second stage friction work (sliding torque $\times$ pitch) is totally transformed in sliding generated heat $\left(H_{\text {Sliding }}\right)$, whereas the plastic strain work (sticking torque $\times$ pitch) is transformed with certain mechanical efficiency $(\eta)$, resulting in the sticking generated heat $\left(H_{\text {Sticking }}\right){ }^{5,7}$ At last, the third stage shows the heat transfer during FSW process, in which certain portion of the total generated heat $\left(H_{\text {Total }}=H_{\text {Sliding }}+H_{\text {Sticking }}\right)$ is lost by conduction through the tool, whereas the remain is the net heat input $(H)$, which produces the thermal field in the plates and later is transferred to ambient by convection and conduction through the plate's sides. ${ }^{3}$ The ratio between net heat input and total generated heat is the thermal efficiency $\left(\eta_{T}\right)$, whose value is commonly in a range between 0.7 and $0.9 .^{3}$ To perform an experimental analysis of the energy transformations during FSW process, electrical current, axial load and thermal cycles were measured during FSW of AA5083 under different welding conditions. From these obtained values, consumed electrical energy, generated heat for pure sliding condition $\left(H_{\text {Sliding }}{ }^{\delta}\right)$ and the net heat input $(H)$ were calculated, respectively, as it is described below. At last, it was possible to calculate the remaining magnitudes of the process which appear in Figure 1, to perform a detailed analysis of them.

\section{Welding and data acquisition}

AA5083 plates of $150 \times 75 \times 3 \mathrm{~mm}$ were butt welded with FSW process with different operating conditions, using an adapted milling 
machine. In Table 1 are shown the welding parameters used for the six different analysed conditions, as well as the resulting pitch number. The $\omega$ and $U$ were varied, whereas tool tilt angle was kept constant in $1.5^{\circ}$ The employed tool was built with $\mathrm{H} 13$ tool steel with a smooth tapered pin and a concave shoulder. The pin length was $2.8 \mathrm{~mm}$, the shoulder diameter was $12 \mathrm{~mm}$ and major and minor diameters were 4 $\mathrm{mm}$ and $3 \mathrm{~mm}$, respectively. During FSW, different process variables were acquired using a data acquisition card of 4 differential channels. Firstly, thermal cycles were measured with two K type thermocouples (TC1 and TC2), which were placed at mid length of the sample, at the advancing side. These were located at different distances of weld centreline, TC1 between 7 and $8 \mathrm{~mm}$ and TC2 between 11 and $12 \mathrm{~mm}$, inside holes with $1 \mathrm{~mm}$ diameter and $2 \mathrm{~mm}$ depth. In Figure
$2 \mathrm{~A}$ is presented the FSW a detail of the thermocouples (TCs) location respect to weld centreline, whereas in Figure 2B is shown a welded sample with the experimental set up. Secondly, the line current $\left(I_{L}\right)$ of the asynchronous three-phase motor of the FSW machine was obtained by using a current transducer with a $10 \mathrm{mV} / \mathrm{A}$ sensitivity and calculating the signal root mean square (rms) value. Finally, the axial loads $(F)$ were measured, for which was employed an installed strain gage located at the machine head. Axial load magnitude was indirectly obtained by acquiring the deformation of the machine head, for which a previous calibration had been performed. Both signals were acquired during welding with the mentioned data acquisition card.

Table I Welding parameters and sample identification

\begin{tabular}{llll}
\hline $\begin{array}{l}\text { Sample } \\
\text { identification }\end{array}$ & $\begin{array}{l}\text { Rotational speed } \\
(\omega)[\mathrm{rpm}]\end{array}$ & $\begin{array}{l}\text { Travel speed } \\
(U)[\mathrm{mm} / \mathrm{min}]\end{array}$ & $\begin{array}{l}\text { Pitch } \\
(\omega / \mathrm{U})[\mathrm{rev} / \mathrm{mm}]\end{array}$ \\
\hline a680-73 & & 73 & 9.3 \\
$680-98$ & 680 & 98 & 6.9 \\
$680-146$ & & 146 & 4.7 \\
$903-73$ & & 73 & 12.4 \\
$903-98$ & 903 & 98 & 9.2 \\
$903-146$ & & 146 & 6.2 \\
\hline
\end{tabular}

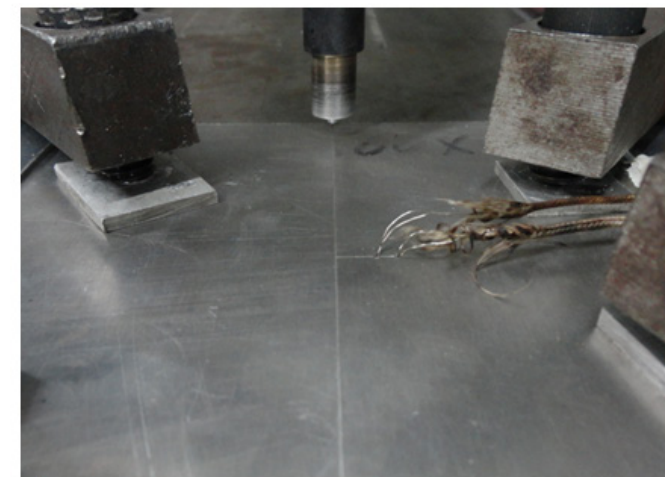

A)

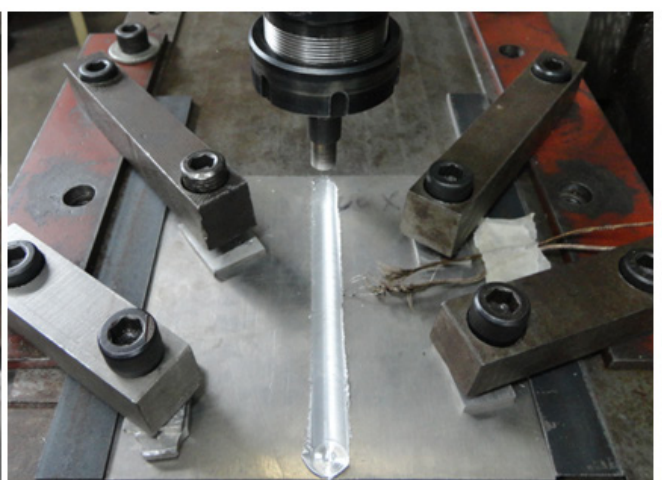

(B)

Figure 2 A) TCs locations for thermal cycles acquisition during FSW, B) Welded sample and FSW experimental set up.

\section{Finite element modelling of heat transfer}

To obtain net values of power $(Q)$ and heat input $(H)$ from acquired thermal cycles, the heat transfer during welding process was modelled by finite element method (FEM). To achieve this, three-dimensional heat transfer was considered only by conduction in the plates, solving the model in a transient way. ${ }^{17}$ The thermal properties of the material were considered constants, whose values were a density of $2660 \mathrm{~kg} /$ $\mathrm{m}^{3}$, a thermal conductivity of $117 \mathrm{~W} /(\mathrm{m} . \mathrm{K})$ and a specific heat of $900 \mathrm{~J} /(\mathrm{kg} . \mathrm{K}) \cdot{ }^{18}$ Heat density generated by the friction between tool shoulder and plates increases with tangential velocity, which is indeed the product between rotational speed and distance to the heat source centre. ${ }^{6,10,12}$ For this reason, in the model it was used a spatial distribution of heat source, linear with distance to tool centre. The heat losses to the ambient by conduction to the backing plate and by convection in the remaining boundary surfaces were considered. Dissipated heat by convection depends on convection coefficient between plate boundary and ambient, which has been considered of $20 \mathrm{~W} /\left(\mathrm{m}^{2} . \mathrm{K}\right) \cdot{ }^{19} \mathrm{It}$ was supposed also that heat transfer towards backing plate is with a large enough solid to not modify its temperature $\left(20^{\circ} \mathrm{C}\right) .{ }^{12}$ This dissipated heat depends on conduction coefficient, which was determined experimentally when finite element model was calibrated. The conduction coefficient resulted to be $200 \mathrm{~W} /\left(\mathrm{m}^{2} . \mathrm{K}\right)$, which is similar to the value reported by other authors. ${ }^{12}$ Net power $(Q)$ was obtained matching the thermal cycles with the numerically obtained ones corresponding to the location of each thermocouple. Then, the neat heat input $(H)$ was calculated as the ratio between net power $(Q)$ and travel speed $(U){ }^{17}$

\section{Macrographic analysis of welded joints}

Cross section samples were extracted from the middle length of different welded joints and were prepared for metallographic observation. By means of Light Microscopy (LM) different characteristics of the welding nugget $(W N)$ were analysed. Particularly, the welding nugget area $(W N A)$ for each welding condition was calculated using an image analysis software. Other aspects related to material flow were also assessed, as penetration or defects presence. 


\section{Results and discussion}

\section{Thermal cycles}

Acquired thermal cycles for the studied welding conditions for extreme values of pitch number (4.7 and 12.4) are shown in Figure 3 . It can be seen significant variations in peak temperatures, cooling rates and duration of the thermal cycles between the maximum pitch value and the minimum one, showing the influence of welding conditions on the generated thermal fields. In Table 2 the characteristic values obtained from the acquired thermal cycles for the different welding conditions are shown. The effective positions referred to weld centreline $\left(y_{T C 1}\right.$ and $\left.y_{T C 2}\right)$ were measured over each sample after welding joints were made. The minor differences between these positions difficult the direct comparison of them, considering the high temperature gradient that take place. Despite that, in general, it was appreciated the fact that maximum temperatures decrease with $U$ for a certain $\omega$ and increases with $\omega$ for a certain $U$, consistently with reported results. ${ }^{1}$ As it has been described on previous section, power $\left(Q_{\text {Net }}\right)$ and heat input $\left(H_{\text {Net }}\right)$ net values were obtained from the position and peak temperature of each thermocouple, using a FEM heat transfer model. $Q_{\text {Net }}$ obtained values were between 322 and $391 \mathrm{~W}$. In general, there was not a significant variation, but it shows a slightly increase with $\omega$, accordingly with the higher peak temperatures. ${ }^{20}$ It was not observed a clear tendency with $U$, consistently with the results found in previous works, where it had been found that net power can be considered nearly independent of $U .7,17,20 H_{\text {Net }}$ varied between 132 and $282 \mathrm{~J} / \mathrm{mm}$, decreasing with $U$ and showing a slight increment with $\omega .6,21$

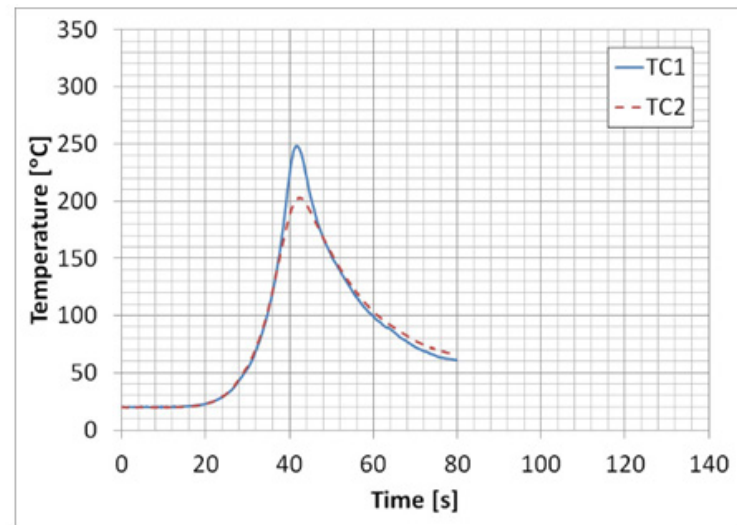

A)

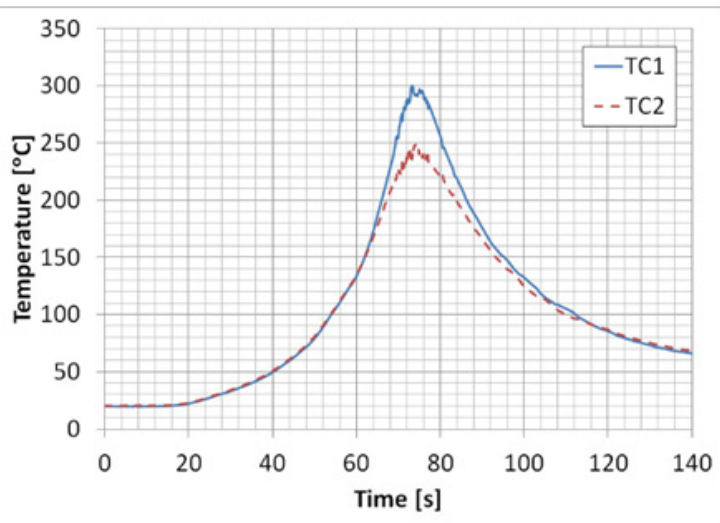

B)

Figure 3 Acquired thermal cycles for extreme pitch values:A) Pitch 4.7 (680- I46), B) Pitch I2.4 (903-73).

Table 2 Characteristic values obtained from acquired thermal cycles

\begin{tabular}{|c|c|c|c|c|c|c|}
\hline \multirow{2}{*}{$\begin{array}{l}\text { Sample } \\
\text { identification }\end{array}$} & \multicolumn{2}{|c|}{ Position $\left(y_{T C_{i}}\right)[\mathrm{mm}]$} & \multicolumn{2}{|c|}{ Maximum temperature $\left[{ }^{\circ} \mathrm{C}\right]$} & \multirow{2}{*}{$\begin{array}{l}\text { Net power } \\
\left(Q_{\text {Net }}\right)[W]\end{array}$} & \multirow{2}{*}{$\begin{array}{l}\text { Net heat input } \\
\left(H_{\mathrm{Net}}\right)[\mathrm{J} / \mathrm{mm}]\end{array}$} \\
\hline & TCI & TC2 & $\mathrm{TCI}$ & TC2 & & \\
\hline $680-73$ & 7.5 & 11.5 & 296 & 257 & 343 & 282 \\
\hline $680-98$ & 7.8 & 11.8 & 290 & 258 & 365 & 223 \\
\hline $680-146$ & 7.2 & II.I & 248 & 203 & 322 & 132 \\
\hline $903-73$ & 7.8 & 11.9 & 295 & 246 & 337 & 277 \\
\hline $903-98$ & 7.3 & 11.7 & 320 & 241 & 391 & 240 \\
\hline $903-146$ & 7.6 & 11.6 & 275 & 262 & 375 & 154 \\
\hline
\end{tabular}

\section{Consumed electrical power and axial load}

Consumed electrical power were calculated from the current measured values using the expression which corresponds to an asynchronous three-phase motor, which is shown in Equation 2, where line tension $\left(V_{L}\right)$ was $380 \mathrm{~V}$, line current $\left(I_{L}\right)$ was the acquired current and power factor $(\cos \phi)$ was considered $0.77 .^{22}$

$$
P=\sqrt{3} \cdot V_{L} \cdot I_{L} \cdot \cos \varphi
$$

In Figure 4 are shown the values of consumed electrical power $(P)$ and axial load $(F 0)$ against time for the extreme conditions of pitch number (4.7 and 12.4). To ease the comparison between both process variables, consumed power does not include the base power $\left(P_{0}\right)$ associated to unloaded condition. At the beginning of the welding, during the tool insertion, it was observed that $P$ and $F$ rise quickly presenting one or two peaks associated to contact of tool pin and shoulder with the sample surface. After these peaks, in general it was observed a drop in both records, due to material softening caused by heat generation and temperature increase. ${ }^{23}$ At first stage, it can be appreciated certain differences between different welding conditions, which were associated to the tool indentation. Later, it was observed that in general $P$ decreased monotonically during the process time, whereas $F$ increased until it reached a maximum value. The decrease of $P$ could be associated to the material flow stress decrease, whereas the increase of the $F$ could be related to the sample dilatation, both caused by the temperature increase. At last, at the end of the welding process, tool is located increasingly near to the sample edge, so that heat diffusion capacity decrease, resulting on a temperature increase. ${ }^{17}$ 
This causes a decrease in material tension flow in a greater degree, as much as the tools shoulder capacity to contain material plastic flow, taking place an increase of the flash and a decrease of $P$ and $F \cdot{ }^{23}$ Similar axial load records during FSW in aluminium alloys had been found in literature. ${ }^{3,5,23,24}$ It had been reported a slow decrease of total torque measured during FSW, ${ }^{3,5}$ which can be related to the electrical current consumed. Schmidt et al. ${ }^{5}$ proposed that the lack of proportionality between both records could be associated to the presence of a sticking component in the heat generation. ${ }^{5}$ Furthermore, the change in this proportion could imply a change in contact condition during welding. After tool insertion, $P$ values had been found generally between 1 and $2.5 \mathrm{~kW}$, whereas maximum $F$ values varied between 6.4 and $8.2 \mathrm{kN}$. Mean consumed electrical power $(\bar{P})$ was obtained directly from temporal integration of the consumed electrical power $(P)$, divided by the total integration time. The mean generated power for pure sliding condition $\left(\bar{Q}_{\text {Sliding }}{ }^{\delta=0}\right)$ is computed in the same way, but it was necessary to calculate the instant values of this power from the axial load $(F)$ records using the expression of the generated sliding power $\left(Q_{\text {Sliding }}\right)$ shown in Equation 3, which arises from heat generation analytical model presented in Section 1

$$
Q_{\text {Sliding }}=(1-\delta) \frac{2}{3} \pi \cdot \omega \cdot \mu \cdot\left(\frac{F}{\pi \cdot R_{s}^{2}}\right)\left[\left(R_{s}^{3}-R_{p}^{3}\right)(1+\tan \alpha)+R_{p}{ }^{3}+3 R_{p}{ }^{2} H_{p}\right]
$$

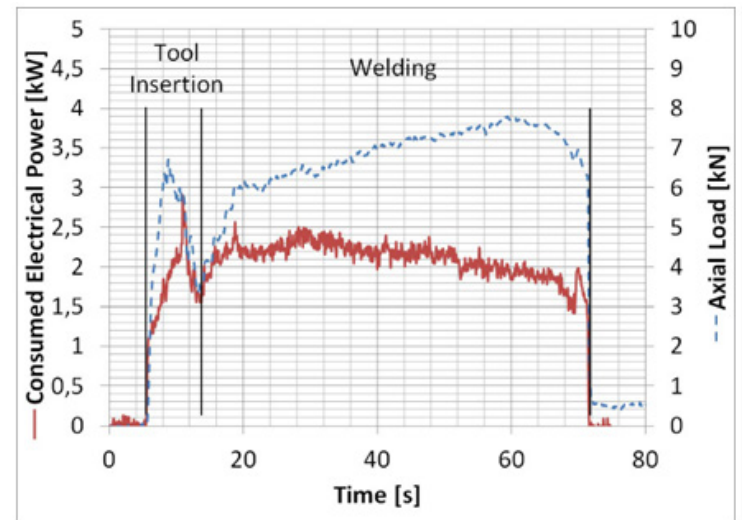

(A)

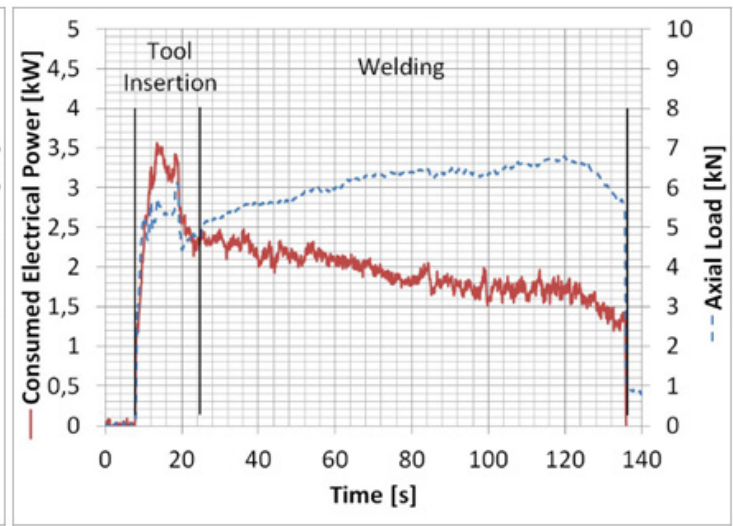

B)

Figure 4 Consumed electrical power and axial load records for extreme pitch values:A) Pitch 4.7 (680-I46), B) Pitch I2.4 (903-73).

On this expression, mean contact pressure $(p)$ is calculated as the ratio between axial load $(F)$ and the projected tool shoulder area. ${ }^{3,5}$ Concerning friction coefficient (), in bibliography can be found a wide range of values used in FSW heat generation models, depending on relative displacement velocity, pressure and temperature. ${ }^{3,25}$ In this work, it was used a coefficient of 0.1 . Finally, the mean power values $\bar{P}$ and $\bar{Q}_{\text {Sliding }}{ }^{\delta=0}$ were divided by travel speed to calculate consumed electrical energy $(E)$ and generated heat for pure sliding $\left(H_{\text {Sliding }}{ }^{=0}\right)$, respectively. In Table 3 these characteristic values obtained from the consumed power and axial load records are shown. The calculation of the $\bar{P}$ was made considering the tool insertion part of the records. The differences observed in the calculated values without considering this tool insertion period were less than $5 \%$, therefore, the adopted criterion has a minor effect in the analysis. $E$ values were in a range between 830 and $1640 \mathrm{~J} / \mathrm{mm}$, whereas $H_{\text {Sliding }}{ }^{\delta=0}$ varied between 91 and $223 \mathrm{~J} / \mathrm{mm}$. Like $H_{N e t}$, these two process variables decreased with $U$, whereas they increase for higher $\omega$.

Table 3 Characteristic values obtained from consumed current $\left(I_{L}\right)$ and axial load $(F)$

\begin{tabular}{lllll}
\hline $\begin{array}{l}\text { Sample } \\
\text { identification }\end{array}$ & $\begin{array}{l}\text { Mean consumed } \\
\text { electrical power } \\
(P)[W]\end{array}$ & $\begin{array}{l}\text { Mean generated } \\
\text { power for pure sliding } \\
\text { condition } \\
\left(Q_{\text {Sliding }}^{-}\right)[W]\end{array}$ & $\begin{array}{l}\text { Consumed electrical } \\
\text { energy } \\
(E)[\mathrm{J} / \mathrm{mm}]\end{array}$ & $\begin{array}{l}\text { Generated heat for pure } \\
\text { sliding condition } \\
\left(H_{\text {Sliding }}\right)[\mathbf{m m}]\end{array}$ \\
\hline $680-73$ & 1790 & 241 & 1470 & 198 \\
$680-98$ & 1800 & 201 & 1100 & 123 \\
$680-146$ & 2020 & 222 & 830 & 91 \\
$903-73$ & 2000 & 272 & 1640 & 223 \\
$903-98$ & 1930 & 273 & 1180 & 167 \\
$903-146$ & 2630 & 317 & 1080 & 130 \\
\hline
\end{tabular}

\section{Heat generation mechanisms}

Figure 5 shows the variation of consumed electrical energy $(E)$ and net heat input $\left(H_{N e t}\right)$ with the pitch number. It can be appreciated that $E$ was significantly greater than $H_{N e t}$ due to the different energy losses mentioned schematically in Figure 1. The observed difference between both magnitudes can be associated to the total process efficiency $\left(\eta_{\text {Total }}\right)$. Also, it is observed that both parameters have increased with pitch number, showing a good correlation with a linear 
tendency, consistently with bibliography. ${ }^{1,20}$ This proportionality can be associated to the fact that $W_{\text {Total }}$ is equal to the product between total torque and pitch number (Figure 1). Thus, a null origin of coordinates was imposed to the obtained linear correlations. From these tendency lines a value for $\eta_{\text {Total }}$ can be obtained by the ratio between both slopes, which results in $18 \%$. This value is particularly for the equipment used in this work and could be strongly dependent of the mechanical efficiency of the machine used.

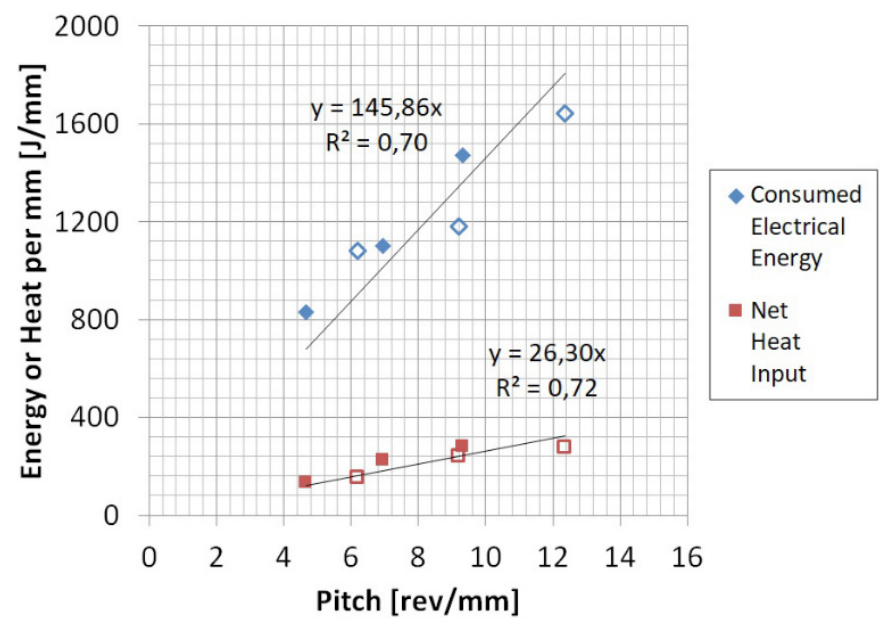

Figure 5 Consumed electrical energy $(E)$ and net heat input $(\mathrm{HNet})$ vs. pitch number. Note: Full markers corresponds to $\omega=680 \mathrm{rpm}$ and empty ones to $\omega=$ $903 \mathrm{rpm}$.

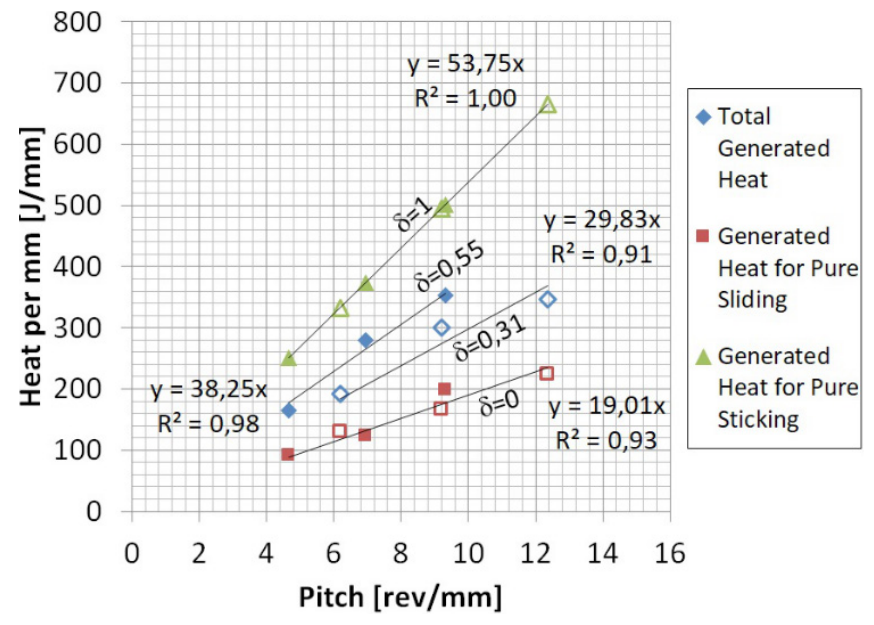

Figure 6 Total generated heat $\left(H_{\text {Total }}\right)$, generated heat for pure sliding $\left(H_{\text {sliding }}^{\delta=0}\right)$ and generated heat for pure sticking $\left(H_{\text {Stiking }}^{\delta=I}\right)$ vs. pitch number. Note: Full markers corresponds to $\omega=680 \mathrm{rpm}$ and empty ones to $\omega=903 \mathrm{rpm}$.

As mentioned before, thermal efficiency $\left(\eta_{T}\right)$ is found commonly between 0.7 and $0.9 .{ }^{3}$ Considering a $\eta_{T}$ of $0.8, H_{\text {Total }}$ can be obtained from the $H_{\text {Net }} H_{\text {Sliding }}^{\delta=0}$ also present a linear tendency with pitch number, showing a good agreement (Figure 6). The generated sticking power $\left(Q_{\text {Sticking }}\right)$ shown in Equation 4 can be computed considering a mechanical efficiency $(\eta)$ of 0.9 and a yield stress $\left(\sigma_{y}\right)$ of $30 \mathrm{MPa}$ associated to a representative condition in the stirred zone for all analysed welding parameters. ${ }^{3,26}$

$$
Q_{\text {Sticking }}=\delta \frac{2}{3} \pi \cdot \omega \cdot \frac{\sigma_{y}}{\sqrt{3}}\left[\left(R_{s}^{3}-R_{p}{ }^{3}\right)(1+\tan \alpha)+R_{p}{ }^{3}+3 R_{p}{ }^{2} H_{p}\right]
$$

Finally, generated heat for pure sticking $\left(H_{\text {Stiking }}{ }^{\delta=I}\right)$ was calculated from $Q_{\text {Sticking }}$. Hence, it was obtained a linear regression with a correlation coefficient of 1 because this heat was not obtained from experimental values (Figure 6). $H_{\text {Total }}$ is equal to the sum of $H_{\text {Sticking }}$ and $H_{\text {Sliding, }}$, as observed in Equation 5.

$$
H_{\text {Total }}=H_{\text {Sticking }}+H_{\text {Sliding }}=\delta \cdot H_{\text {Sticking }}^{\delta=1}+(\delta-1) \cdot H_{\text {Sliding }}^{\delta=0}
$$

This equation also shows that limit values for $H_{\text {Total }}$ are the $H_{\text {Sliding }} \delta=0$ and $H_{\text {Stiking }}{ }^{\delta=1}$. This aspect can also be appreciated in Figure 6, where obtained values of $H_{\text {Total }}$ were located in an intermediate zone between both limit values. Furthermore, the proximity of $H_{\text {Total }}$ with each one of the limit values is associated with sticking rate $(\delta)$, which can be calculated from correlations of Figure 6 and Equation 5. Obtained values were 0.55 and 0.31 for $\omega$ of 680 and $903 \mathrm{rpm}$, respectively. This result indicates that for lower $\omega$ a contact condition nearer to pure sticking was obtained, which produced a higher $H_{\text {Total }}$ This $\delta$ variation with $\omega$ is consistent with bibliography and is considered by several authors for the development of FSW models..$^{7-9,20}$ The developed analysis can be applied to different welding conditions and materials, reaching a deeper understanding of the heat generation mechanisms 
acting in FSW process for each case. From the expressions obtained in Figure 6 and considering the $\delta$ values can be calculated $H_{\text {Sticking }}$ and
$H_{\text {Sliding }}$ for each $\omega$, and its variation with the pitch number is shown in Figure 7.

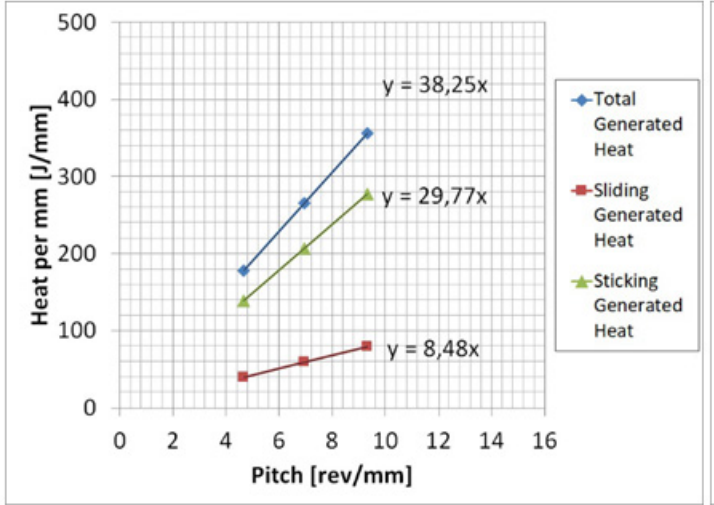

(A)

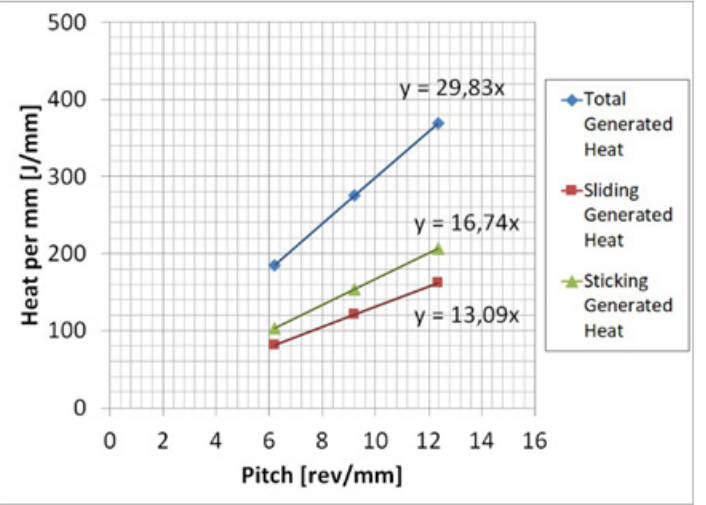

(B)

Figure 7 Total generated heat $\left(H_{\text {Total }}\right)$, sliding generated heat $\left(H_{\text {sliding }}\right)$ and sticking generated heat $\left(H_{\text {Sticking }}\right)$ variations with pitch number: a. 680 rpm, b. 903 rpm.

It can be observed that for both cases $H_{\text {Sticking }}$ was greater than $H_{\text {Sliding }}$, although contact condition was closer to pure sliding for $903 \mathrm{rpm} .{ }^{16}$ This result shows that a contact condition closer to pure sliding $(903 \mathrm{rpm})$ do not imply that the sliding heat is greater than sticking heat, which is because $H_{\text {Sliding }}{ }^{\delta}=0$ is the lower limit for $H_{\text {Total }}$. This fact indicates that the main heat generation mechanism in FSW is in general sticking, associated to the plastic deformation of the material. The slopes of the linear correlations obtained in Figure 6 , are associated with torque values for each $\omega$, (expressed in $\mathrm{J} /$ rev, which means $\mathrm{Nm} /(2 \pi))$. This imply that torque does not vary significantly with $U$, accordingly with bibliography. ${ }^{7,14,20,27}$ In this way, both sliding torque $\left(T_{\text {Sliding }}\right)$ and sticking torque $\left(T_{\text {Sticking }}\right)$ can be calculated from the expressions of the Figure 7. $T_{\text {Sliding }}$ equals the slope of the $H_{\text {Sliding }}$ correlation, which was 1.4 and $2.1 \mathrm{Nm}$ for 680 and $903 \mathrm{rpm}$, respectively. For the sticking component, must be considered the mechanical efficiency $(\eta)$ of 0.9 , so that $T_{\text {Sticking }}$ resulted to be 5.3 and $3.0 \mathrm{Nm}$ for 680 and $903 \mathrm{rpm}$, respectively. As it was expected, the torque components presented the same behaviour as heat components. Even though a decrease in $\omega$ produced a decrease in sticking component and an increase in sliding component, the $T_{\text {Sticking }}$ was greater that $T_{\text {Sliding }}$ in both cases, although contact condition was closer to pure sliding for $903 \mathrm{rpm}$. Total torque $\left(T_{\text {Total }}\right)$ was obtained by the sum of both torque components, which resulted to be 6.6 and $5.0 \mathrm{Nm}$ for 680 and $903 \mathrm{rpm}$, respectively. Values of $T_{\text {Total }}, T_{\text {Sliding }}$ and $T_{\text {Sticking }}$ were of the same order of those reported by other authors for similar welded joints. ${ }^{8} T_{\text {Total }}$ decreases with $\omega$, accordingly with the bibliography. $4,7,9,13,14,20,27$ Other authors proposed that this decrease could be associated to the fact that the material can flow easier at higher temperatures. ${ }^{7,20}$ Although an effect of temperature exists on material flow stress, it does not explain completely the involved phenomena since in Figure 6 it can be observed that for a same $\omega$, the generated heat increases with a decrease in $U$, without a significant variation in $T_{\text {Total }}$. Furthermore, some authors have suggested that the increase of $\omega$ produces a strain rate increase that improves the material flow. ${ }^{7,20}$ However, in agreement with different models used for this material, that increase in the strain rate produces an increase in flow stress. ${ }^{28}$ Instead, the analytical model used in this work, that do not consider the variation of the material flow stress with temperature and strain rate, shows that the decrease in $T_{\text {Total }}$ with the $\omega$ can only be associated to the decrease in $\omega$. Therefore, it can be concluded that the mentioned decrease is mainly due to the decrease of the $\omega, \mathrm{i}$. e., the change in contact condition at the tool-workpiece interface.

Finally, it was possible to obtain the exclusive FSW process efficiency $\left(\eta_{F S W}\right)$, calculating the ratio between $H_{N e t}$ and $W_{\text {Total }}$ at the tool and it resulted $75 \%$, showing a small variation with the contact condition. The $\eta_{F S W}$ depends on $\eta_{T}$ and $\eta$, which are took from bibliography, but it is not possible to obtain the $\eta_{F S W}$ directly from them because $\eta$ only affects the $H_{\text {Sticking }}$. The value of $\eta_{F S W}$ is around the obtained experimentally from $T_{\text {Total }}$ measurements by Gallais et al., which had resulted to be $60 \% .^{12}$ Then, since the total process efficiency $\left(\eta_{\text {Total }}\right)$ equals the product between $\eta_{F S W}$ and the machine efficiency $\left(\eta_{\text {Mach }}\right)$, it was possible to calculate the last one, which resulted $24 \%$. The $\eta_{\text {Mach }}$ was considerably lower and similar to $\eta_{\text {Total }}$, in comparison with $\eta_{T}$ and $\eta$. This result indicates that low $\eta_{\text {Total }}$ obtained previously is associated to ${ }_{\text {Mach }}$. As it was mentioned before, the $\eta_{\text {Mach }}$ depends on the equipment employed, which will be possibly higher for machines with advanced technology than the one used for this work, so that $E$ could be lower. In the future is expected to be able to measure $T_{\text {Total }}$ at the tool to improve the obtained results and go further into experimental analysis about energetic balance of FSW process.

\section{Material flow}

Cross sections macrographs of the welding joints are shown in Figure 8 , indicating the calculated $W N A$ for each case. Defect free and full penetration joints were obtained for all welding conditions. A defect free $W N$ indicates that an adequate material flow is achieved during the welding process. Changes in the shape and size of the $W N$ with the and $U$ can be appreciated. The material flow in the $\mathrm{WN}$ is composed by two flows, one related with the tool shoulder action (upper zone and wider) and other with the tool pin one (lower central zone and narrower). ${ }^{29}$ These variations in the $W N$ were observed in both zones, thus the components of sticking and sliding would affect both types of material flow. For the lower $U$, the shape is smoother, and the size is bigger, which are related with a higher volume of stirred material. An increase in $U$, generates a sharper and smaller $W N$, especially for $903 \mathrm{rpm}$. Figure $9 \mathrm{~A}$ shows the welding nugget area $(W N A)$ vs. pitch. The $W N A$ rises linearly with the pitch number for the same $\omega$ (or $\delta$ ), similarly to the observed for the $H_{\text {Total }}$ vs pitch (Figure 6). This behaviour is related to the fact that a decrease in $U$ produces 
an increase in $H_{\text {Total }}$, which implies that a higher volume of material achieves an adequate temperature to flow properly, without affecting the capability of the tool of driving the material flow associated to the $\delta$ and $\omega$, resulting in a higher $W N A$. On the other hand, an increase in $\omega$ produces a slight increment in $H_{\text {Total }}$ with a decrease in $\delta$, which produces an increase in the extent of sliding at the tool-work piece interface, reducing the capability of the tool of driving the material flow and consequently the size of the $W N$. Therefore, it can be said that the material flow depends on $H_{\text {Total }} \omega$ and $\delta . H_{\text {Sticking }}$ is related with these three magnitudes. Figure 9B. Shows that $W N A$ has a direct relation with $H_{\text {Sticking }}$ for all the welding conditions. This behaviour implies that the selection of welding parameters in $F S W$ to obtain sound welds should consider the extent of $H_{\text {Sticking }}$ which improves the material flow during welding, according with Arora et al. proposal of maximize the sticking torque to enhance the material flow. ${ }^{8}$
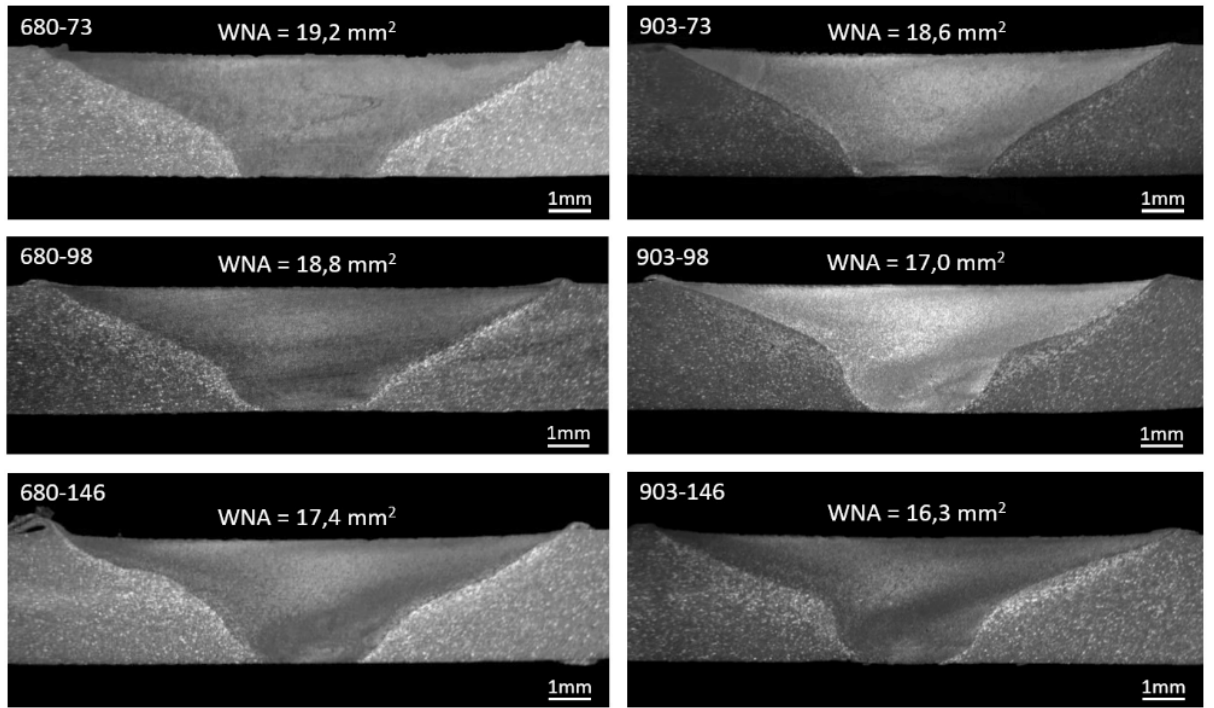

Figure 8 Macrographs of welding joints.

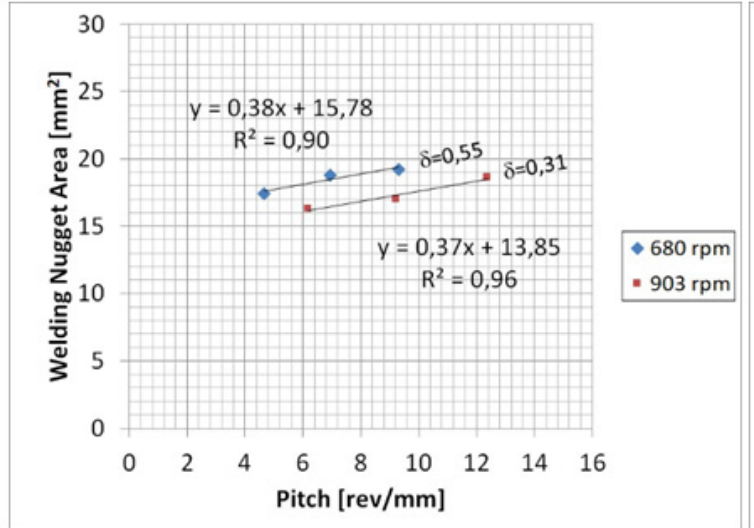

(A)

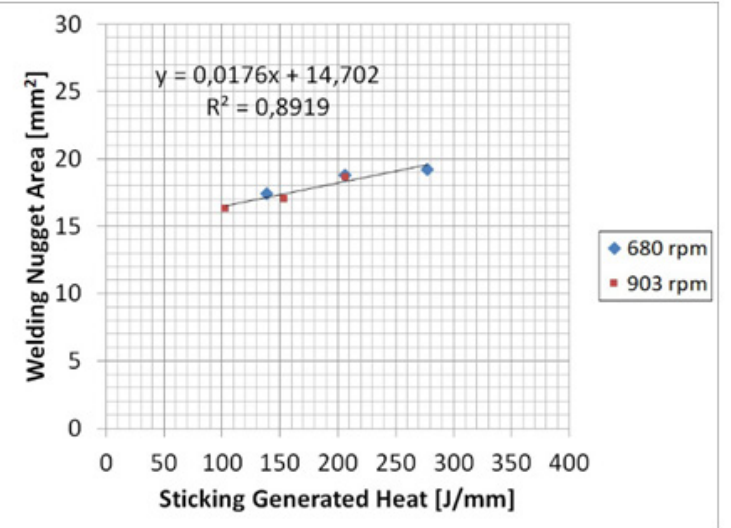

(B)

Figure 9 A) Weld Nugget Area (WNA) vs. Pitch, B) Weld Nugget Area (WNA) vs. Sticking Generated Heat $\left(H_{\text {sticking }}\right)$.

\section{Conclusions}

1. From experimental measurements of electrical current, axial load and thermal cycles during FSW of AA5083 plates for different rotational and travel speeds, and simple analytical and numerical models it was proposed an original methodology to quantify the magnitudes associated to the energy transformations which take place during FSW in order to perform an analysis of the heat generation mechanisms and its effects in material flow.

2. Consumed electrical energy and the net heat input increased linearly with pitch number. There were obtained the experimental expressions with good correlation factor and the total process efficiency.

3. Variations in contact condition at the interface tool-work piece was evaluated. Sticking rate is defined by tool rotational speed, decreasing with its increase. The obtained values for 680 and $903 \mathrm{rpm}$ were 0.55 and 0.31 , respectively.

4. Sticking and sliding generated heat components were estimated, as well as its variation with pitch number. As the sticking rate decreases, the total and sticking generated heat decreases and the sliding generated heat increases. Despite of that, sticking heat was greater than sliding heat for the analysed conditions. 
Contact condition closer to sliding do not imply that the sliding heat is greater than sticking heat, because the generated heat for pure sliding $(\delta=0)$ is the lower limit for total generated heat. This fact indicates that the main heat generation mechanism in FSW would be in general sticking, associated to the plastic deformation of the material.

5. The slope of the linear equations obtained were related to the torque. Both components of torque were calculated, showing a similar behaviour to the generated heat. Total torque resulted to be 6.6 and $5.0 \mathrm{Nm}$ for 680 and $903 \mathrm{rpm}$, respectively, which means that total torque decreases with rotational speed. Despite the effect of temperature on material flow stress, this behaviour is mainly due the sticking rate decrease.

6. The weld nugget area was measured for the different welding conditions, decreasing with rotational and travel speed. There was shown that the sticking generated heat controls the weld nugget area, directly affecting the material flow.

7. The obtained results agree with the tendencies previously observed for other authors, validating the proposed methodology. It can be extended to other materials and welding conditions, being a useful tool to reach a deeper understanding of the FSW process and to optimize the welding procedure.

\section{Acknowledgments}

The authors acknowledge to Universidad de Buenos Aires, Agencia Nacional de Promoción Científica y Tecnológica (ANPCYT) and Instituto Nacional de Tecnología Industrial for the funding and the facilities in order to develop this work and also to the personnel of Instituto de Tecnologías y Ciencias de la Ingeniería and Centro de Investigación y Desarrollo en Mecánica for its collaboration.

\section{Conflicts of interest}

The authors declare that there is no conflict of interest.

\section{References}

1. Mishra RS, Ma ZY. Friction stir welding and processing. Mater Sci Eng R. 2005;50:1-78.

2. Mishra RS, Mahoney MW. Friction Stir Welding and Processing. 1st edn. Ohio. ASM International; 2007.

3. Schmidt HNB. Modelling thermal properties in friction stir welding. In: Friction stir welding. 1st edn. Woodhead Publishing; 2010:277-313.

4. Colligan KJ, Mishra RS. A conceptual model for the process variables related to heat generation in friction stir welding of aluminum. Scr Mater. $2008 ; 58: 327-331$.

5. Schmidt H, Hattel J, Wert J. An analytical model for the heat generation in friction stir welding. Modell Simul Mater Sci Eng. 2003;12:143-157.

6. Simar A, Bréchet Y, De Meester B, et al. Integrated modeling of friction stir welding of 6xxx series Al alloys: process, microstructure and properties. Prog Mater Sci. 2012;57:95-183.

7. Arora A, Nandan R, Reynolds AP, et al. Torque, power requirement and stir zone geometry in friction stir welding through modelling and experiments. Scr Mater. 2009;60:13-16.

8. Arora A, De A, Debroy T. Toward optimum friction stir welding tool shoulder diameter. Scr Mater. 2011;64:9-12.

9. Mehta M, Chatterfee K, De A. Monitoring torque and traverse force in friction stir welding from input electrical signatures of driving motors. Sci Technol Weld Joining. 2013;18:191-197.
10. Schmidt HB, Hattel JH. Thermal modelling of friction stir welding. Scr Mater. 2008;58:332-337.

11. Chen G, Feng Z, Zhu Y, et al. An alternative frictional boundary condition for computational fluid dynamics simulation of friction stir welding. $J$ Mater Eng Perform. 2016;25:4016-4023.

12. Gallais C, Denquin A, Bréchet $Y$, et al. Precipitation microstructures in an AA6056 aluminium alloy after friction stir welding: Characterisation and modelling. Mater Sci Eng A. 2008;496:77-89.

13. Su H, Wu CS, Pittner A, et al. Thermal energy generation and distribution in friction stir welding of aluminum alloys. Energy. 2014;77:720-731.

14. Andrade DG, Leitão C, Dialami, N, et al. Modelling torque and temperature in Friction Stir Welding of Aluminium Alloys. Int $J$ Mech Sci. 2020;182:105725.

15. Wang X, Gao Y, Liu X, et al. Tool-workpiece stick-slip conditions and their effects on torque and heat generation rate in the friction stir welding. Acta Mater. 2021;213:116969.

16. Buglioni L, Tufaro LN, Svoboda HG. CFD Numerical Model Development For Friction Stir Welding Of Aluminum Alloys. Proceedings of the XXXVI Iberian Latin-American Congress on Computational Methods in Engineering. Rio de Janeiro. 2015.

17. Tufaro LN, Svoboda HG. Estudio de los Ciclos Térmicos Adquiridos durante FSW mediante Modelos Analíticos y Numéricos. Anais $38^{\circ}$ Congresso Nacional de Soldagem, Ouro Preto. 2012.

18. ASM Handbook. Volume 2, Properties and Selection: Nonferrous Alloys and Special-Purpose Materials. 2nd edn. Ohio. ASM International; 1992.

19. Mills AF. Transferencia de Calor. 1st edn. Irwin, México. 1995.

20. Nandan R, Debroy T, Bhadeshia HKDH. Recent advances in friction-stir welding - Process, weldment structure and properties. Prog Mater Sci. 2008;53:980-1023.

21. Peel MJ, Steuwer A, Withers PJ, et al. Dissimilar friction stir welds in AA5083-AA6082. Part I: process parameter effects on thermal history and weld properties. Metall Mater Trans A. 2006;37:2183-2193.

22. Senthil Kumar S, Denis Ashok S, Narayanan S. Investigation of Friction Stir Butt Welded Aluminium Alloy Flat Plates using Spindle Motor Current Monitoring Method. Procedia Eng. 2012;64:915-925.

23. Kumar R, Singh K, Pandey S. Process forces and heat input as function of process parameters in AA5083 friction stir welds. Trans Nonferrous Met Soc China. 2012;22:288-298.

24. Trimble D, Monaghan J, O'Donnell GE. Force generation during friction stir welding of AA2024-T3. CIRP Annals - Manufacturing Technology. 2012;61:9-12.

25. Mohktar A. Simulation of Friction Stir Spot Welding (FSSW) Process Study of Friction Phenomena. College of Engineering and Mineral Resources at West Virginia University. 2007.

26. Kim D, Chung K, Badarinarayan H. An experimental and numerical approach to evaluate the effect of welding conditions on temperature during friction stir spot welding. In: Trends in Welding Research. Proceedings of the 8th International Conference. 2009;8:60-66.

27. Leitão C, Louro R, Rodrigues DM. Using torque sensitivity analysis in accessing Friction Stir Welding/Processing conditions. $J$ Mater Process Technol. 2012;212:2051-2057.

28. Chen S, Hwu Y, Ou Y, et al. An Investigation into Hot Deformation Resistance of an AA5083 Alloy. China Steel Technical Report. 2012;25:60-65.

29. Kumar KSVK, Kailas SV. The role of friction stir welding tool on material flow and weld formation. Mater Sci Eng A. 2008;485:367-374. 